\title{
Keragaman dan Kelimpahan Plankton di Perairan Rawa Pening Ambarawa Kabupaten Semarang
}

\section{Plankton Diversity and Abundance in Rawa Pening Ambarawa, Semarang}

\author{
Yovita Widya Asmara ${ }^{1}$, Agatha Sih $\mathrm{P}^{2}$, Dwi Nugroho $\mathrm{W}^{3}$ \\ ${ }^{1,2,3)}$ Fakultas Biology Universitas Jenderal Soedirman, Purwokerto \\ ${ }^{1)}$ Surakarta; jovangelino@gmail.com
}

\begin{abstract}
INTISARI
Keberadaan bahan-bahan anorganik dan organik yang berasal dari sungai, sisa pakan, sisa metabolisme ikan, dan sisa pembusukan makrofita air dapat menjadi sumber nutrien. Salah satu organisme yang hidup di Rawa Pening Ambarawa adalah plankton yang dapat digunakan untuk mengevaluasi kestabilan komunitas pada perairan dengan mengkaji keragaman dan kelimpahannya. Penelitian yang bertujuan untuk mengetahui keragaman dan kelimpahan plankton perairan Rawa Pening Ambarawa Jawa Tengah ini dilakukan dari bulan Juli sampai September 2006. Metode yang digunakan adalah metode survei dan pengambilan sampel dibagi menjadi 3 zona (zona hulu, tengah, dan hilir) dengan 3 stasiun pada setiap zona. Data yang dikumpulkan adalah jumlah spesies dan jumlah individu serta parameter fisika kimia air perairan Rawa Pening. Analisis data yang digunakan adalah analisis secara deskriptif dan aturan $50 \%$. Hasil penelitian menunjukkan keragaman plankton yang ditemukan pada zona hulu sebanyak 30 genera dengan kelimpahan plankton 2.227 ind/l, pada zona tengah sebanyak 31 genera dengan kelimpahan plankton 2.753 ind/I, dan pada zona hilir sebanyak 29 genera dengan kelimpahan plankton 1.215 ind/l. Berdasarkan hasil penelitian, keragaman dan kelimpahan plankton pada zona hulu, tengah, dan hilir adalah sama
\end{abstract}

Kata kunci: keragaman, kelimpahan, plankton

\begin{abstract}
The existence of organic and inorganic materials which come from river, food waste, fish metabolism waste, and aquatic macrophyte decomposed waste could become the source of nutrient. One of organism which life in Rawa Pening Ambarawa is plankton that can be used to evaluate community stability on waters by investigate it diversity and abundance. The research to know the diversity and abundance of waters plankton at Rawa Pening, Ambarawa, Central Java has been conducted from July to September 2006. The research site used a survey the sample were taken and the sampling sites were divided into 3 zones (inlet, middle, and outlet zones), with 3 stations on each zone. The parameters were the number of species and individual. The supporting parameters were water physical chemistry of Rawa Pening. The data were analyzed using descriptive analysis and $50 \%$ rules. Result of research showed that the diversity of plankton which found in inlet zone counted as 30 genera with plankton abundance 2,227 ind/l, in middle zone counted as 31 genera with plankton abundance 2,753 ind/l, and
\end{abstract}


in outlet zone counted as 29 genera with plankton abundance 1,215 ind/l. Based on the result, the diversity and abundance of plankton in inlet, middle, and outlet zones is spread evenly.

Keywords : diversity, abundance, plankton

\section{PENDAHULUAN}

Fungsi utama perairan Rawa Pening adalah penyimpan air untuk pembangkit listrik, irigasi, perikanan, dan objek wisata. Pemanfaatan di bidang perikanan dengan adanya budidaya ikan dengan keramba jaring apung. Budidaya ikan ini memberikan kontribusi nutrien dari sisa pakan dan sisa metabolisme ikan yang akan mempengaruhi keragaman dan kelimpahan plankton (Sumule, 2005).

Menurut Balitbangda Jateng (2003), tataguna lahan pada Daerah Aliran Sungai (DAS) perairan Rawa Pening merupakan areal tegalan, persawahan, pemukiman, dan lahan perkebunan. Sebagai inlet dari beberapa sungai yang masuk, perairan Rawa Pening mengalami beban masukan nutrien dan sedimen yang cukup tinggi. Adanya sedimentasi dan pengayaan nutrien tersebut dapat mempengaruhi keragaman dan kelimpahan plankton.

Keragaman dan kelimpahan plankton di perairan dapat ditunjukkan dengan komunitas populasi plankton disertai dengan jumlah individu plankton per liter air (Krebs, 1978). Kelimpahan suatu organisme dapat digunakan sebagai suatu petunjuk kondisi lingkungan perairan sebagai bioindikator wilayah (Saha, 2002).

Ekosistem perairan Rawa Pening mempunyai rona lingkungan yang berbeda sehingga menimbulkan perbedaan zona. Daerah masuknya (inlet) sumber air yang berasal dari sungai disebut zona hulu. Zona tengah merupakan daerah genangan terbesar, dan zona hilir (outlet) merupakan daerah keluarnya air

Adanya perbedaan rona lingkungan di perairan Rawa Pening akan menyebabkan perbedaan keragaman dan kelimpahan plankton. Berdasarkan uraian tersebut, maka tujuan penelitian ini adalah untuk mengetahui keragaman dan kelimpahan plankton pada zona hulu, tengah, hilir di perairan Rawa Pening, Ambarawa, Kabupaten Semarang dan mengetahui perbedaan keragaman dan kelimpahan plankton antar zona di perairan Rawa Pening, Ambarawa, Kabupaten Semarang. Hasil penelitian ini diharapkan dapat memberikan informasi mengenai keragaman dan kelimpahan plankton di perairan Rawa Pening Ambarawa Kabupaten Semarang. Informasi yang diperoleh dapat digunakan sebagai salah satu data pemantau kestabilan ekosistem perairan Rawa Pening.

\section{MATERI DAN METODE PENELITIAN}

\section{A. Materi, Lokasi dan Waktu Penelitian}

Obyek penelitian yang diamati adalah plankton dan sampel air Rawa Pening Kabupaten Semarang. Bahan yang digunakan dalam penelitian ini adalah sampel plankton, sampel air, dan bahanbahan untuk analisis $\mathrm{O}_{2}$ terlarut, $\mathrm{CO}_{2}$ bebas, nitrat, ortofosfat. Alat yang digunakan dalam penelitian ini adalah plankton net No. 25, ember plastik, kantong plastik, botol sampel, dan mikroskop binocular.

Penelitian ini dilaksanakan di Rawa Pening Ambarawa Kabupaten Semarang. Pengamatan dan identifikasi plankton dilakukan di Laboratorium Pengajaran Fakultas Biologi, Unsoed Purwokerto. Analisis TSS, nitrat, dan ortofosfat dilakukan di Wahana Laboratorium Semarang. Penelitian dilaksanakan selama tiga bulan yaitu Juli-September 2006. 


\section{B. Metode Penelitian}

Penelitian ini menggunakan metode survey dengan teknik pengambilan sampel Group Random sampling. Penentuan lokasi pengambilan sampel berdasarkan rona lingkungan yang berbeda yaitu pada zona hulu, tengah, dan hilir. Masing-masing zona diwakili 3 stasiun pengambilan sampel. Lokasi pengambilan sampel sebagai berikut :

Zona Hulu :

1. Stasiun I pada muara Muncul

2. Stasiun II pada daerah Kebon Dowo

3. Stasiun III pada daerah Swaru

Zona Tengah :

1. Stasiun IV pada daerah keramba Tengalit

2. Stasiun V pada daerah keramba Kebun Dowo

3. Stasiun VI pada daerah keramba Segalok

Zona Hilir :

1. Stasiun VII pada daerah Kilen Cikal

2. Stasiun VIII pada daerah Kalimati

3. Stasiun IX pada daerah Blondo

Pengambilan sampel dilakukan sebanyak 3 kali dengan interval waktu 1 bulan. Parameter yang diukur adalah parameter utama yang meliputi jumlah jenis dan jumlah individu plankton, dan parameter pendukung yang meliputi penetrasi cahaya, temperatur, $\mathrm{pH}, \mathrm{O}_{2}$ terlarut, $\mathrm{CO}_{2}$ bebas, TSS, nitrat, dan ortofosfat.

\section{Metode Analisis Data}

1. Keragaman dan kelimpahan

Mengetahui keragaman dan kelimpahan plankton dengan mengetahui komposisi plankton pada tingkat genera dan jumlah individu dianalisis secara deskriptif.

2. Untuk membandingkan keragaman dan kelimpahan Untuk membandingkan kelimpahan antar lokasi pengambilan sampel berdasarkan struktur komunitasnya dilakukan analisis Aturan
50\% (Kendeigh, 1980), dengan menggunakan rumus Kelimpahan Relatif sebagai berikut:

$K R=\frac{n i}{N} x 100 \%$

Keterangan :

$\mathrm{KR}=$ kelimpahan relatif $(\%)$

$\mathrm{ni}=$ jumlah individu tiap genera

$\mathrm{N}=$ jumlah total individu

Takson yang predominan (p)

dan non predominan (-) ditentukan terlebih dahulu pada masing-masing stasiun yang dibandingkan. Genera yang predominan adalah genera yang jumlah individunya relatif banyak (minimal 10\%) dari jumlah seluruh individu. Apabila tidak terdapat jumlah yang minimal, maka takson yang predominan adalah semua takson yang dalam sampel bersama-sama membentuk paling sedikit $90 \%$ dari seluruh individu sampel kemudian ditentukan status dari takson-takson yang predominan pada masing-masing stasiun, yaitu:

1. Ubiquotus : takson yang terdapat pada setiap stasiun pengamatan dengan jumlah yang hampir sama banyak.

2. Eksklusif : takson yang terdapat pada satu stasiun pengamatan tetapi tidak ada pada stasiun pengamatan yang lain.

3. Karakteristik : takson yang terdapat pada satu stasiun pengamatan tetapi sedikit pada stasiun pengamatan yang lain (kriteria perbandingan 1:3). Ubiquotus : takson yang terdapat pada setiap stasiun pengamatan dengan jumlah yang hampir sama banyak.

Stasiun pengamatin yang dibandingkan dengan cara 4 dapat dinyatakan berbeda apabila paling sedikit $50 \%$ dari takson predominan pada stasiun pengamatan yang dibandingkan tersebut berstatus eksklusif atau paling tidak berstatus karakteristik (Kendeigh, 1980). 
Tabel I. Kekayaan genera tiap divisi dan phylum plankton yang ditemukan di perairan Rawa Pening Ambarawa

\begin{tabular}{|c|c|c|c|c|}
\hline \multirow[t]{2}{*}{ No. } & \multirow[t]{2}{*}{ Divisi/phylum } & \multicolumn{3}{|c|}{ Jumlah genera tiap zona } \\
\hline & & \multicolumn{3}{|c|}{ Zona } \\
\hline \multicolumn{2}{|c|}{ Fitoplankton } & Hulu & Tengah & Hilir \\
\hline 1 & Cyanophyta & 3 & 4 & 3 \\
\hline 2 & Chlorophyta & 6 & 10 & 7 \\
\hline 3 & $\begin{array}{l}\text { Chrysophyta } \\
\text { (Diatomae) }\end{array}$ & 11 & 5 & 9 \\
\hline \multirow[t]{2}{*}{4} & Euglenophyta & 1 & 1 & 0 \\
\hline & $\begin{array}{l}\text { Jumlah genera } \\
\text { fitoplankton }\end{array}$ & 21 & 20 & 19 \\
\hline \multicolumn{5}{|c|}{ Zooplankton } \\
\hline 1 & Arthropoda & 3 & 4 & 3 \\
\hline 2 & Protozoa & 4 & 5 & 5 \\
\hline \multirow[t]{2}{*}{3} & Rotifera & 2 & 2 & 2 \\
\hline & $\begin{array}{l}\text { Jumlah genera } \\
\text { zooplankton }\end{array}$ & 9 & 11 & 10 \\
\hline \multicolumn{2}{|c|}{ Total genera plankton } & 30 & 31 & 29 \\
\hline
\end{tabular}

\section{HASIL DAN PEMBAHASAN}

\section{A. Keragaman dan Kelimpahan Plankton}

\section{Keragaman Plankton}

Keragaman genera plankton yang ditemukan pada perairan Rawa Pening tersaji dalam Tabel I. Berdasarkan Tabel I tersebut terlihat bahwa keragaman plankton yang ditemukan zona hulu sebanyak 30 genera, pada zona tengah ditemukan 31 genera, dan pada zona hilir ditemukan 29 genera. Keragaman plankton yang ditemukan pada tiap zona mempunyai jumlah yang hampir sama dengan selisih yang sangat sedikit, sehingga dapat dikatakan keragaman plankton tiap zona adalah sama.

Keragaman plankton yang sama pada tiap zona disebabkan oleh kondisi kualitas perairan yang tidak jauh berbeda atau hampir sama di setiap zona yaitu temperatur, nilai $\mathrm{pH}$, kandungan $\mathrm{O}_{2}$ terlarut, dan kandungan $\mathrm{CO}_{2}$ bebas. Kondisi kualitas perairan di Rawa Pening mendukung pertumbuhan dan kehidupan plankton.

Fitoplankton yang ditemukan yaitu divisi Cyanophyta, Chlorophyta, Chrysophyta, dan Euglenophyta. Divisi
Cyanophyta penyebarannya merata di setiap zona (Tabel I). Cyanophyta merupakan plankton yang mempunyai sifat yang tahan kekeringan dan tahan panas sehingga dapat hidup dalam jangka yang lama (Vashista, 1981). Chlorophyta penyebarannya merata di setiap zona. Zona hulu terdapat 6 genera, zona tengah 10 genera, dan zona hilir 7 genera. Chlorophyta merupakan alga terbesar di air tawar. Hal ini sesuai dengan pendapat Sachlan (1982), yaitu Chlorophyta merupakan alga terbesar di air tawar.

$$
\text { Chrysophyta merupakan }
$$
fitoplankton yang penyebarannya sangat luas. Pada zona hulu diperoleh 11 genera, zona tengah diperoleh 5 genera, dan zona hilir ditemukan 9 genera. Vashista (1981) menyatakan bahwa Chrysophyta mempunyai penyebaran yang sangat luas atau disebut kosmopolit. Menurut Sachlan (1982), Chrysophyta mempunyai daya reproduksi yang cepat.

Euglenophyta secara kualitas dan kuantitas relatif rendah, ini disebabkan karena Euglenophyta mempunyai flagel yang digunakan untuk bergerak. Sachlan (1982) menyatakan bahwa Euglenophyta mempunyai bentuk tubuh sel oval memanjang, pada mulut sel terdapat 
cambuk atau flagel, dan dapat digunakan untuk bergerak.

Zooplankton yang ditemukan yaitu Phylum Arthropoda, Protozoa, dan Rotifera. Phylum Arthropoda mempunyai penyebaran yang luas dari berbagai kondisi lingkungan perairan. Wetzel (1983) menyatakan bahwa phylum Arthropoda mempunyai kemampuan beradaptasi yang tinggi terhadap perubahan faktor lingkungan.

Phylum Protozoa merupakan zooplankton yang paling tinggi keragamannya di setiap zona. Protozoa (Class Ciliata dan Rhizopoda) dapat digunakan sebagai indikator daerah perairan yang mengandung bahan organik tinggi atau terjadinya pembusukan (Ryadi, 1984). Ini menggambarkan bahwa perairan Rawa Pening banyak terjadi pembusukan makrofita akuatik. Phylum Rotifera merupakan zooplankton sejati dalam perairan tawar atau payau.

\section{Kelimpahan Plankton}

Kelimpahan plankton total yang ditemukan pada perairan Rawa Pening adalah sebanyak 6.194 ind/1 seperti yang tersaji dalam Tabel II.

Tabel II. Kelimpahan plankton yang ditemukan pada tiap zona di perairan Rawa Pening Ambarawa

\begin{tabular}{|c|c|c|c|c|}
\hline \multirow[b]{3}{*}{ Plankton } & \multicolumn{4}{|c|}{ Kelimpahan plankton tiap zona (ind/1) } \\
\hline & \multicolumn{3}{|c|}{ Zona } & \multirow[b]{2}{*}{ Total } \\
\hline & Hulu & Tengah & Hilir & \\
\hline Fitoplankton & 1.789 & 2.071 & 1.009 & 4.869 \\
\hline Zooplankton & 438 & 681 & 206 & 1.325 \\
\hline Total & 2.227 & 2.752 & 1.215 & 6.194 \\
\hline
\end{tabular}

Kelimpahan plankton rata-rata yang ditemukan pada zona hulu yaitu 2.227 ind/l. Kelimpahan plankton ratarata zona tengah yaitu 2.752 ind/l. Kelimpahan plankton rata-rata zona hilir yaitu 1.215 ind/l (Tabel II). Kelimpahan plankton rata-rata pada zona tengah paling tinggi dibanding dengan kelimpahan plankton rata-rata pada zona hulu dan hilir. Kelimpahan yang tinggi ini disebabkan pada zona tengah mempunyai kandungan hara yang tertinggi yaitu berupa nitrat dan ortofosfat. Nitrat dan ortofosfat ini merupakan unsur yang sangat penting dalam memacu pertumbuhan plankton terutama fitoplankton. Kandungan rata-rata nitrat $7,81 \mathrm{mg} / \mathrm{l}$ dan kandungan rata-rata ortofosfat sebesar $0,05 \mathrm{mg} / 1$.

Tingginya nitrat pada zona tengah sangat mendukung perkembangan dan pertumbuhan plankton sehingga kelimpahannya tertinggi dibandingkan dengan dua zona lainnya yaitu zona hulu dan hilir. Kelimpahan plankton terendah dijumpai pada zona hilir (Tabel II), berkaitan dengan kandungan hara yang berupa nitrat dan ortofosfat yang paling rendah dibanding zona tengah dan zona hilir. Kandungan rata-rata nitratnya sebesar $6,51 \mathrm{mg} / 1$ sedangkan kandungan rata-rata ortofosfatnya sebesar $0,04 \mathrm{mg} / 1$.

Zona hilir mempunyai nilai ratarata penetrasi cahaya yang paling kecil yaitu $54,22 \mathrm{~cm}$ dan nilai rata-rata TSS yang terbesar dibanding zona lainnya yaitu 91,02 mg/l. Kandungan TSS pada zona hilir cenderung lebih besar sebab zona hilir merupakan zona penumpukan sedimen dan memiliki kedalaman yang rendah, sehingga dengan adanya pengaruh arus, sedimen cenderung lebih mudah bercampur dengan air.

Berdasarkan Tabel II tampak bahwa kelimpahan fitoplankton rata-rata pada zona tengah paling banyak dibanding dengan zona hulu dan zona hilir. Hal ini disebabkan zona tengah merupakan daerah yang mempunyai kandungan hara yang tinggi yaitu nitrat dan ortofosfat dibanding dengan zona lainnya. Faktor lain yang menyebabkan kelimpahan 
fitoplankton terbesar pada zona tengah yaitu bahwa zona tengah mempunyai nilai rata-rata penetrasi cahaya yang tertinggi dibanding zona lainnya yaitu $120,94 \mathrm{~cm}$. Menurut Odum (1971) penetrasi cahaya pada suatu perairan berperan sangat penting bagi organisme akuatik berklorofil dalam melakukan aktivitas fotosintesis.

Hasil penelitian menunjukkan bahwa kelimpahan fitoplankton lebih tinggi dibanding dengan zooplankton (Tabel II). Hal ini dikarenakan fitoplankton pada ekosistem perairan berperan sebagai produsen primer yaitu mata rantai utama dalam rantai makanan sedangkan zooplankton sebagai konsumen primer yaitu mata rantai kedua (Odum, 1971). Menurut Davis (1955) kelimpahan zooplankton akan mengikuti kelimpahan fitoplankton. Sachlan (1982) menambahkan bahwa jumlah zooplankton berada dibawah fitoplankton.

B. Perbedaan Keragaman dan Kelimpahan Plankton

Perbedaan keragaman dan kelimpahan plankton yang di analisis menggunakan Aturan 50\% dapat dilihat dalam Tabel III.

Tabel III. Genera plankton yang predominan dan statusnya pada perairan Rawa Pening Ambarawa

\begin{tabular}{|c|c|c|c|c|c|c|c|c|c|c|}
\hline \multirow[t]{2}{*}{$\begin{array}{l}\mathbf{N} \\
\mathbf{o}\end{array}$} & & \multicolumn{2}{|c|}{ Zona } & \multirow[t]{2}{*}{ Status } & \multicolumn{2}{|c|}{ Zona } & \multirow[t]{2}{*}{$\begin{array}{c}\text { Statu } \\
\text { s }\end{array}$} & \multicolumn{2}{|c|}{ Zona } & \multirow{2}{*}{$\begin{array}{c}\text { Statu } \\
\mathrm{s}\end{array}$} \\
\hline & Genera & Hulu & $\begin{array}{c}\text { Tenga } \\
\mathrm{h}\end{array}$ & & Hulu & Hilir & & $\begin{array}{c}\text { Tenga } \\
\mathrm{h}\end{array}$ & Hilir & \\
\hline \multirow[t]{2}{*}{1.} & $\begin{array}{c}\text { Spirogyr } \\
\mathrm{a}\end{array}$ & $\begin{array}{c}31,93 \\
\%\end{array}$ & $37,90 \%$ & $\mathrm{U}$ & $\begin{array}{c}31,93 \\
\%\end{array}$ & $\begin{array}{c}18,27 \\
\%\end{array}$ & $\mathrm{U}$ & $37,90 \%$ & $\begin{array}{c}18,27 \\
\%\end{array}$ & $\mathrm{U}$ \\
\hline & & (p) & (p) & & (p) & (p) & & (p) & (p) & \\
\hline \multirow[t]{2}{*}{2.} & $\begin{array}{c}\text { Nitzschi } \\
\text { a }\end{array}$ & $\begin{array}{c}20,07 \\
\%\end{array}$ & $18,46 \%$ & & $\begin{array}{c}20,07 \\
\%\end{array}$ & $\begin{array}{c}18,93 \\
\%\end{array}$ & $\mathrm{U}$ & $18,46 \%$ & $\begin{array}{c}18,93 \\
\%\end{array}$ & $\mathrm{U}$ \\
\hline & & $(-)$ & $(-)$ & & $(-)$ & (p) & & $(-)$ & (p) & \\
\hline \multirow[t]{2}{*}{3.} & Synedra & $6,62 \%$ & $1,82 \%$ & & $6,62 \%$ & $\begin{array}{c}23,05 \\
\%\end{array}$ & K & $1,82 \%$ & $\begin{array}{c}23,05 \\
\%\end{array}$ & K \\
\hline & & $(-)$ & $(-)$ & & $(-)$ & (p) & & $(-)$ & (p) & \\
\hline
\end{tabular}

\footnotetext{
Keterangan:

(p) = predominan

$(-)=$ non predominan

$\mathrm{U}=$ ubiquotus

$\mathrm{K}=$ karakteristik
}

Hasil uji Aturan 50\% antar zona dapat diketahui bahwa keragaman dan kelimpahan pada zona hulu, tengah, dan hilir tidak berbeda menurut genera penyusunnya. Genera predominan yang berstatus ubiquotus (U) dijumpai sebanyak $5(71,43 \%)$ dan yang berstatus karakteristik (K) sebanyak 2 (28,57\%) sehingga dapat dikatakan bahwa keragaman plankton antar zona yaitu zona hilir, tengah, dan hulu hampir sama dan kelimpahan plankton antar zona merata.

Keragaman dan kelimpahan plankton yang hampir sama pada tiap zona disebabkan adanya kondisi kualitas air yang tidak jauh berbeda atau hampir sama seperti temperatur air, $\mathrm{pH}, \mathrm{O}_{2}$ terlarut, dan $\mathrm{CO}_{2}$ bebas. Pengukuran temperatur air pada perairan Rawa Pening diperoleh dengan kisaran $25,89-27,00^{\circ} \mathrm{C}$. Menurut Goldman \& Horne (1983) temperatur air yang baik untuk perkembangan plankton berkisar $20-30^{\circ} \mathrm{C}$. Pengukuran $\mathrm{pH}$ pada perairan Rawa Pening diperoleh dengan kisaran 6,606,99 . Nilai $\mathrm{pH}$ yang ideal bagi kehidupan organisme air pada umumnya adalah 6-8,5 (Barus, 2001). Kandungan $\mathrm{CO}_{2}$ bebas 
rata-rata yang didapat $10,10-14,20 \mathrm{mg} / \mathrm{l}$. Effendi (2003) menyatakan bahwa kadar $\mathrm{CO}_{2}$ bebas sebesar $10 \mathrm{mg} / 1$ masih bisa ditolerir organisme akuatik asal disertai dengan kadar $\mathrm{O}_{2}$ terlarut yang cukup. Kandungan $\mathrm{O}_{2}$ terlarut yang didapat adalah 4,88-5,75 mg/l. Boyd (1988) dalam Effendi (2003) mengatakan bahwa kandungan $\mathrm{O}_{2}$ terlarut $>5 \mathrm{mg} / \mathrm{l}$ baik untuk semua organisme akuatik.

Kondisi kualitas perairan pada perairan Rawa Pening mendukung pertumbuhan dan kehidupan plankton. Kualitas perairan yang sama tiap zona menyebabkan keragaman dan kelimpahan plankton yang sama.

\section{KESIMPULAN DAN SARAN}

\section{A. Kesimpulan}

Berdasarkan hasil penelitian keragaman dan kelimpahan plankton di perairan Rawa Pening Ambarawa dapat disimpulkan bahwa :

1. Keragaman dan kelimpahan plankton yang ditemukan selama penelitian yaitu zona tengah (31 genera, 2.227 ind/1) mempunyai nilai yang paling tinggi dibanding zona hulu (30 genera, 2.753 ind/l), dan hilir (29 genera, 1.215 ind $/ 1)$.

2. Keragaman dan kelimpahan plankton pada zona hulu, tengah dan hilir adalah sama.

\section{B. Saran}

Hasil penelitian tentang keragaman dan kelimpahan plankton di perairan Rawa Pening ini merupakan sumber informasi kekayaan biodiversitas, akan tetapi perlu diadakannya penelitian yang berkesinambungan untuk memantau keragaman dan kelimpahan plankton antar zona guna mengetahui perubahanperubahan yang terjadi pada perairan Rawa Pening Ambarawa.

\section{Ucapan Terima Kasih}

Terimakasih kepada Dra. Agatha Sih P, M.Sc dan Dr. Dwi Nugroho W, MS, selaku dosen pembimbing yang telah memberikan banyak bimbingan dan arahan.

\section{Daftar Referensi}

Badan Penelitian dan Pengembangan Provinsi Jawa Tengah. 2003. Penelitian Karakteristik Rawapening, Semarang.

Barus, T. A. 2001. Limnologi. Dirjen Pendidikan Tinggi, Jakarta.

Davis, C. C. 1955. The Marine and Fresh Water Plankton. Michigan State University Press, The Advance Lighraphi Co, Chicago-USA.

Effendi, H. 2003. Telaah Kualitas Air bagi Pengelolaan Sumberdaya dan Lingkungan Perairan. Jurusan Manajemen Sumberdaya Perairan. Fakultas Perikanan dan Ilmu Kelautan Institut Pertanian Bogor, Bogor.

Goldman, C. R. and A. J. Horne. 1993. Limnology. MC Graw-Hill Book Company, Tokyo.

Kendeigh, S.C. 1980. Ecology with Special Reference to Animal and Man. Prentice-Hall Priv. Ltd, New Delhi.

Krebs, C.J. 1978. Ecologycal Experiment Analysis on Distribution and Abudance. Harper and Row Publication, New York.

Odum, E. P. 1971. Fundamentals of Ecology. W. B Saunder, Toronto.

Ryadi, S. 1984. Pencemaran Air. Dasardasar dan Pokok-pokok Penanggulangannya. Karya Anda, Surabaya.

Saha, J. K. 2002. Plankton Biodiversity in Boro Beel, Pabna, Bangladesh. URL

http://fli.hws.edu/pdf/conferenc e2005/JKSaha.pdf. diakses 26 Juli 2006. 
Sachlan, M. 1982. Planktonologi. Fakultas

Peternakan dan Perikanan Universitas Diponegoro,

Semarang.

Sumule, O. 2005. Limbah Nitrogen pada Budidaya Ikan Mas di Perairan
Danau dan Waduk. Alami, 10 : 31-35.

Vashista, B. R. 1981. Botany For Degree Student Part I Algae. United State National, Holt, New York.

Wetzel, R. G. 1983. Limnology. Sounders College Publishing, Philadelphia 